\title{
Effects of the use of fortified raw maternal milk on very low birth weight infants
}

\author{
Evelyn C. Martins, ${ }^{1}$ Vera L. J. Krebs ${ }^{2}$
}

\begin{abstract}
Objective: To compare the weight and height gain and the frequency of clinical complications in preterm newborns weighing less than $1,500 \mathrm{~g}$, exclusively fed human milk or fortified human milk until reaching 1,800 g.

Methods: Prospective double-blind randomized controlled trial involving 40 preterm infants weighing $<1,500 \mathrm{~g}$ at birth and $\leq 34$ weeks of gestational age, admitted to a neonatal intensive care unit from August 2005 to April 2007. Preterm infants were randomized into two groups: control (human milk) and intervention (fortified human milk). Fortifiers were added to manually expressed human milk when feeding volume reached $100 \mathrm{~mL} / \mathrm{kg} /$ day until newborns reached $1,800 \mathrm{~g}$. Daily weight gain, weekly length and head circumference gain, nutritional variables and clinical complications were compared.
\end{abstract}

Results: Human milk fortification resulted in better growth, with length gain of 1.09 and $0.87 \mathrm{~cm} /$ week $(p=0.003)$ and head circumference gain of 0.73 and $1.02 \mathrm{~cm} /$ week $(p=0.0001)$, respectively, for intervention and control groups. The weight gain was 24.4 and $21.1 \mathrm{~g} /$ day $(p=0.075)$. There were no significant clinical complications.

Conclusions: Human milk fortification resulted in better growth, significant increase in length and head circumference.

J Pediatr (Rio J). 2009;85(2):157-162: Human milk fortification, human milk, very low birth weight infant, premature, growth.

\section{Introduction}

Nutrition of very low birth weight preterm newborn is a challenge for the multiprofessional team due to special conditions such as accelerated metabolism, decrease in body reserves, higher risk of complications associated with digestive system immaturity and reduced adaptation capacity when there is water-electrolyte imbalance. ${ }^{1,2}$

The concern with providing nutrients to preterm infants can be explained by the need to promote rate of physical growth and development similar to those of intrauterine life at the same gestational age. ${ }^{3}$ Due to a higher concentration of proteins, fat, calories, electrolytes and minerals, in addition to the maintenance of specific bioactive function, protection against infections, cognitive and gastrointestinal function and development of mother-infant bond, maternal milk is considered the best option to feed very low birth weight preterm infants. ${ }^{4-6}$

In spite of the several advantages of breastfeeding, some studies demonstrated that preterm newborns fed exclusively human milk had lower growth rates than the growth rates of intrauterine life. ${ }^{7}$ Preterm newborns weighing less than 1,500 $\mathrm{g}$ at birth and fed exclusively non-fortified human milk had lower growth and lower serum levels of calcium and phosphorus in comparison with newborns fed fortified human milk until their weight reached $1,800 \mathrm{~g} .{ }^{8}$ Therefore, several authors recommend the use of fortified human milk with the purpose of meeting nutritional needs $\mathrm{s}^{9-12}$ and preventing bone demineralization in these children. ${ }^{13}$

1. Mestre. Departamento de Pediatria, Faculdade de Medicina, Universidade de São Paulo (USP), São Paulo, SP, Brazil. Nutricionista, Santa Casa de Misericórdia de Passos, Passos, MG, Brazil. Docente, Universidade do Estado de Minas Gerais (UEMG), Belo Horizonte, MG, Brazil.

2. Professora livre-docente, Pediatria, Faculdade de Medicina, USP, São Paulo, SP, Brazil. Chefe, Berçário Anexo à Maternidade, Hospital de Clínicas, Faculdade de Medicina, USP, São Paulo, SP, Brazil.

No conflicts of interest declared concerning the publication of this article.

Suggested citation: Martins EC, Krebs VL. Effects of the use of fortified raw maternal milk on very low birth weight infants. J Pediatr (Rio J). 2009;85(2):157-162.

Manuscript received Oct 15 2008, accepted for publication Jan 262009.

doi:10.2223/JPED.1878 
To date, there are no comparative studies between two groups fed exclusively raw maternal milk during the whole period of study. This fact is explained by the great difficulty of expressing enough raw maternal milk while the very low birth weight preterm newborn remains in hospital, as well as due to the high cost of fortifiers.

The objective of this study is to compare weight and height gain and frequency of clinical complications in preterm newborns weighing less than $1,500 \mathrm{~g}$ fed exclusively fortified or non-fortified raw maternal milk until their weight reached $1,800 \mathrm{~g}$.

\section{Methods}

Prospective double-blind randomized controlled trial involving 40 preterm newborns weighing less than $1,500 \mathrm{~g}$ at birth and $\leq 34$ weeks of gestational age, admitted to a neonatal intensive care unit (NICU) from August 2005 to April 2007. Newborns who met the inclusion criteria, and whose mothers were able to express their own milk, were randomized to receive exclusive pure human milk (control group) or fortified human milk (intervention group). Of the 67 preterm newborns whose birth weight was $<1,500 \mathrm{~g}$ admitted during the period of study, 23 were excluded because they were being fed other type of milk, three died due to sepsis and one was excluded for suffering from necrotizing enterocolitis before starting to receive diet of $100 \mathrm{~mL} / \mathrm{kg} /$ day. Other exclusion criteria were: impairment of gastrointestinal tract, congenital malformation and neurological impairment. Double-blind randomization was carried out by drawing lots performed by the physician(s) on duty using a sequence of numbers from 1 to 20 for each group. The results of randomization were recorded so that the researcher was blind to which group the newborn belonged to. Mothers expressed their milk in an exclusive room and, when their child was allocated to the intervention group, fortifier was added to their milk in the milk storage room by the nurses on duty according to the study protocol (at pre-defined time of feeding and concentration), and, next, the milk was given to the newborn at the NICU. The researcher was blind to which group the newborns belonged to and also did not know which newborn was receiving pure or fortified human milk.

Based on the estimates of Mukhopadhyay et al. for small for gestational age newborns who have characteristics similar to those in the present study, the difference in the weight gain was $3.0 \mathrm{~g} / \mathrm{kg} /$ day, weighted standard deviation of 4.0 $\mathrm{g} / \mathrm{kg} /$ day (4.3 for control group and 3.6 for intervention group), significance level of $5 \%$ and power of $80 \%$. The estimate for the size of the sample in a comparison of means between two groups (Student's $t$ test) was 20 in each group. ${ }^{14}$

Parents or guardians signed the written consent form. The present study was approved by the Research Ethics Committee of Santa Casa de Misericórdia de Passos, Passos, state of Minas Gerais, Brazil, on August 10, 2005, and by the Ethics
Committee for Analysis of Projects and Research (CAPPEsq) of Hospital das Clínicas of School of Medicine of Universidade de São Paulo on June 28, 2006 (protocol no. 573/06).

Newborns weighing $<1,500 \mathrm{~g}$ at birth received parenteral nutrition on the first day, around $60 \mathrm{kcal} / \mathrm{kg} /$ day, and an open orogastric tube was used to drain the gastric residue. Next, newborns started receiving $1 \mathrm{~mL}$ of maternal milk every 3 hours, with increase of 16 to $24 \mathrm{~mL} /$ day when there were good clinical status and diet acceptance. Newborns received mixed nutrition (parenteral + enteral) until enteral nutrition reached $60 \mathrm{kcal} / \mathrm{kg} / \mathrm{day}$. Then, parenteral nutrition was ceased, and enteral nutrition was evolved until it became full nutrition (160 $\mathrm{mL} / \mathrm{kg} /$ day). Newborns were paired by gender and age, fed exclusively raw maternal milk and randomized until reaching fluid intake of $100 \mathrm{~mL} / \mathrm{kg} /$ day, when the intervention group started receiving fortified milk. The fortifier was added at a concentration of $3 \%$ during 5 days and, then, $5 \%$ until the newborn's weight reached $1,800 \mathrm{~g}$. After gaining the expected weight, at the end of the period of comparison and use of fortifier, newborns were transferred to an intermediate care unit and remained there until reaching $2 \mathrm{~kg}$ and being breastfed, which are the criteria for hospital discharge. The fortifier (Fortified Milk $85^{\circledR}$ ), whose composition was valid for use in 2005 , was added at every feeding time, which happened every 3 hours. The product used was taken from the same lot and had the same composition during the whole period of study. The composition in $20 \mathrm{~mL}$ of human milk with $1 \mathrm{~g}$ of fortifier ( $5 \%$ ), described in the package (produced in 2005), is $0.4 \mathrm{~g}$ of protein, $0.8 \mathrm{~g}$ of fat, $2.1 \mathrm{~g}$ of carbohydrate, $21 \mathrm{mg}$ of calcium, 12 $\mathrm{mg}$ of phosphorus, $7 \mathrm{mg}$ of sodium, $45 \mathrm{mcg}$ of vitamin A, 9 mcg of folic acid, $3 \mathrm{mg}$ of vitamin C, $0.46 \mathrm{mcg}$ of vitamin $\mathrm{K}$ and $17 \mathrm{kcal}$ ( $30 \%$ more than pure human milk). We used only raw maternal milk, manually expressed just before being offered to the newborns and/or, at most, for the three following feeding times. The stored milk was kept refrigerated. This procedure was performed in the room for manual expression of milk at the hospital, in compliance with the pre-defined rules of the Ministry of Health.

The following variables were analyzed: daily weight gain, weekly length and head circumference gain, digestive intolerance (vomiting and/or gastric residue), abdominal distension, infection episode, hypernatremia, jaundice, duration of mechanical ventilation and duration of: fasting, parenteral nutrition, mixed nutrition (parenteral + enteral), exclusive enteral nutrition, age when started diet of $100 \mathrm{~mL} / \mathrm{kg} /$ day and age when started receiving full nutrition ( $160 \mathrm{~mL} / \mathrm{kg} / \mathrm{day})$. A volume larger than $50 \%$ of the volume received was considered an important amount of gastric residue. Infection episode was defined as presence of clinical evidence of infection and positive culture (blood culture or urine culture). Serum concentration of $\mathrm{Na} \geq 150 \mathrm{mEq} / \mathrm{L}$ was considered hypernatremia. ${ }^{15}$

Weight was measured at birth and daily using digital neonatal scale (Filizola ${ }^{\mathrm{TM}}$ and model BP Baby) with accuracy of 


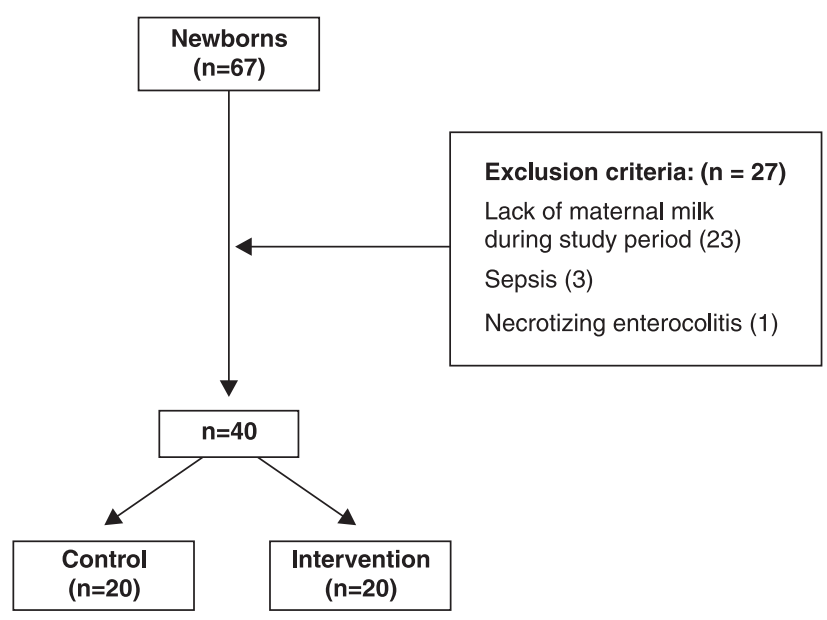

Figure 1 - Study design

125 to $2,500 \mathrm{~g}$. Newborns' weight was checked by the researcher in the mornings every day after infants had been fed for the third time. When there was gastric tube or venous access device, 5 and $20 \mathrm{~g}$, respectively, were deducted from the final weight. Newborns were followed-up until their weight reached $1,800 \mathrm{~g}$.

Their length was measured by the researcher once a week. Newborns were in supine position on a hard surface, and the researcher used an anthropometer (wooden graduated ruler), placing the fixed end of the ruler at the top of the newborn's head and moving the mobile end of the ruler up to the feet sole, avoiding knee flexion. Head circumference was measured by the researcher once a week, starting at the most prominent projecting point of the occiput and using an inextensible measuring tape.

The descriptive statistics of frequencies, mean and standard deviation were presented. For analysis of associations and comparisons of variables between the groups, we used
Pearson's chi-square test or Fisher's exact test. For parametric variables we used Student's $t$ test and, for non-parametric variables, we used Mann-Whitney test. We considered the association as statistically significant for values of $p<0.05$.

\section{Results}

Forty very low birth weight preterm infants were included in the present study. Based on the selective criteria, we excluded 27 newborns as shown in Figure 1. Groups were similar regarding birth weight, length, gender and gestational age at the beginning of the study (Table 1 ).

The intervention group, which received fortified milk, had a weight gain of $24.4 \mathrm{~g} /$ day until reaching $1,800 \mathrm{~g}$, compared to $21.1 \mathrm{~g} /$ day of the control group, $(p=0.075)$. There was significant difference in the mean increase in length and head circumference in the group that received fortified milk. Fluid intake of $100 \mathrm{~mL} / \mathrm{kg} /$ day was reached on the 14th and 15th day of admission on average, and full diet $(160 \mathrm{~mL} / \mathrm{kg} /$ day $)$ was started on the 19th and 20th day of admission in the intervention and control groups, respectively. With regards to length of hospital stay, we found that the intervention group stayed in hospital 3 days longer than the control group until reaching $1,800 \mathrm{~g}$. This is due to the lower mean weight of the intervention group at the beginning of the study. However, both variables did not show statistical difference, and these 3 days were not taken into consideration in the comparisons performed every week (7 days). For the variables: fasting, parenteral nutrition, parenteral + enteral nutrition, exclusive enteral nutrition and mechanic ventilation, the groups did not show significant difference (Table 2).

Complications found in the control and intervention groups were, respectively: digestive intolerance, 28 and $18 \%$; abdominal distension, 10 and $20 \%$; hypernatremia, 5 and 0\%; infection episodes, 25 and 20\% (Table 3).

\section{Discussion}

At the beginning of the study, the groups were similar, and there was not statistically significant difference between birth

Table 1 - Characteristics of control and intervention groups at the beginning of the study

\begin{tabular}{|c|c|c|c|c|}
\hline & $\begin{array}{l}\text { Control group } \\
\qquad \begin{array}{c}(n=20) \\
n(\%)\end{array}\end{array}$ & $\begin{array}{l}\text { Intervention group } \\
(\mathbf{n}=20) \\
n(\%)\end{array}$ & $\begin{array}{c}\text { Total } \\
(n=40) \\
n(\%)\end{array}$ & p* \\
\hline Female & $9(45)$ & $8(40)$ & $17(42,5)$ & 0.749 \\
\hline Male & $11(55)$ & $12(60)$ & $23(57,5)$ & \\
\hline SGA & $7(35)$ & $9(45)$ & $16(40)$ & 0.519 \\
\hline AGA & $13(65)$ & $11(55)$ & $24(60)$ & \\
\hline Weight $(\mathrm{g})^{+}$ & $1,220 \pm 272.88$ & $1,195.25 \pm 261.20$ & $24.75 \pm 84.47$ & 0.771 \\
\hline Length $(\mathrm{cm})^{+}$ & $38.25 \pm 2.56$ & $36.9 \pm 3.10$ & $1.35 \pm 0.90$ & 0.141 \\
\hline
\end{tabular}

AGA = appropriate for gestational age; SGA = small for gestational age.

* Pearson's chi-square test.

+ Mean \pm standard deviation. 
Table 2 - Comparison (mean \pm standard deviation) of anthropometric and nutritional variables between the groups after intervention period

\begin{tabular}{|c|c|c|c|}
\hline Variables & Control group & Intervention group & $\mathbf{p}$ \\
\hline Weight gain (g/day) & $21.2 \pm 5.5$ & $24.4 \pm 5.6$ & $0.075^{*}$ \\
\hline Length gain ( $\mathrm{cm} /$ week) & $0.87 \pm 0.2$ & $1.09 \pm 0.2$ & $0.003 *$ \\
\hline $\begin{array}{l}\text { Head circumference gain (cm/ } \\
\text { week) }\end{array}$ & $0.73 \pm 0.16$ & $1.02 \pm 0.21$ & $0.0001 *$ \\
\hline $\begin{array}{l}\text { Age when reached diet of } 100 \\
\mathrm{~mL} / \mathrm{kg} / \text { day }\end{array}$ & $15.6 \pm 6.9$ & $14.1 \pm 5.3$ & $0.418^{*}$ \\
\hline $\begin{array}{l}\text { Age when reached full nutrition } \\
(160 \mathrm{~mL} / \mathrm{kg} / \text { day })\end{array}$ & $20.0 \pm 3.1$ & $19.1 \pm 2.9$ & $0.503 *$ \\
\hline Length of hospital stay (days) & $29.5 \pm 14.0$ & $33.1 \pm 16.0$ & $0.464 *$ \\
\hline Fasting (days) & $1.4 \pm 1.19$ & $1.4 \pm 0.69$ & $0.461^{+}$ \\
\hline Parenteral nutrition (days) & $1.6 \pm 1.19$ & $2.4 \pm 3.22$ & $0.706^{+}$ \\
\hline $\begin{array}{l}\text { Parenteral + enteral nutrition } \\
\text { (days) }\end{array}$ & $7.6 \pm 3.55$ & $6.3 \pm 3.44$ & $0.265^{+}$ \\
\hline $\begin{array}{l}\text { Exclusive enteral nutrition } \\
\text { (days) }\end{array}$ & $33.0 \pm 18.2$ & $39.2 \pm 15.3$ & $0.252^{+}$ \\
\hline Mechanical ventilation (days) & $17.9 \pm 13.5$ & $15.5 \pm 11.5$ & $0.541^{+}$ \\
\hline
\end{tabular}

* Student's $t$ test.

${ }^{\dagger}$ Mann-Whitney test.

Table 3 - Comparison of the frequency of complications between the groups

\begin{tabular}{lcccc}
\hline Complication & $\begin{array}{c}\text { Control group } \\
\mathbf{n}(\mathbf{\%})\end{array}$ & $\begin{array}{c}\text { Intervention group } \\
\mathbf{n}(\%)\end{array}$ & $\begin{array}{c}\text { Total } \\
\mathbf{n}(\%)\end{array}$ & p* \\
\hline Infection & $5(25)$ & $4(20)$ & $9(22.5)$ & 1.000 \\
Digestive intolerance $^{+}$ & $11(28)$ & $7(18)$ & $18(45)$ & 0.340 \\
Abdominal distension & $2(10)$ & $4(20)$ & $6(15)$ & 0.661 \\
Hypernatremia & $1(5)$ & $0(0)$ & $1(2.5)$ & 1.000 \\
Jaundice & $0(0)$ & $1(5)$ & $1(2.5)$ & 1.000 \\
\hline
\end{tabular}

* Fisher's exact test.

${ }^{+}$Vomiting and/or gastric residue $>50 \%$ of the volume received.

weight, length and the other variables. Analyzing weight and length gain, we found that the weight gain of newborns who received fortified raw maternal milk was $24.4 \mathrm{~g} /$ day, whereas the group that received pure human milk gained $21.2 \mathrm{~g} /$ day $(p=0.075)$. In terms of length, there was an increase of 1.09 $\mathrm{cm} /$ week in the group that received fortified milk and 0.87 $\mathrm{cm} /$ week in the group that received pure human milk, with statistical difference $(p=0.003)$. The increase in head circumference was 0.73 and $1.02 \mathrm{~cm} /$ week $(p=0.0001)$ in the control and intervention groups, respectively.

Several authors have demonstrated that the use of fortifiers in raw and/or processed human milk in milk banks results in higher weight and length gain in very low birth weight preterm infants, in addition to preventing metabolic bone disease. ${ }^{16-19}$ However, to date, there are no studies on weight and length gain of very low birth weight preterm infants using fortifiers exclusively in raw maternal milk. Published studies used milk formula, ${ }^{3,14}$ or milk from milk banks to complement the diet. 8,20 This fact is probably due to the great difficulty of obtaining enough raw maternal milk during the whole period the preterm newborn stays in hospital.

In a systematic review, ${ }^{21} 13$ studies on the use of fortified human milk in very low birth weight preterm infants were analyzed. The main objective of the authors was to determine the impact of milk supplementation on growth, bone metabolism and neurological development. All randomized or quasi-randomized studies predominantly published in English were included. The results showed that human milk supplementation using different types of fortifiers is associated with 
short-term increase in weight, length and head circumference gain. There were no important alterations in the serum levels of alkaline phosphatase or clearly detectable effects on bone mineralization. Therefore, such variables were not analyzed and investigated in the present study. There was increase in the blood urea nitrogen concentrations, in addition to slight decrease in $\mathrm{pH}$, with no clinical consequences. The authors concluded that the use of fortified human milk is associated with short-term improvement in weight gain, linear and head growth. Data obtained in the 13 studies, involving approximately 600 children, were not sufficient to assess long-term neurological development and growth. Therefore, it was not possible to establish enough evidence of benefits or adverse effects after the first year of life.

In a prospective randomized study involving 170 very low birth weight preterm infants, who received diet including at least $80 \%$ of maternal milk, the authors found daily weight gain of 15.1 and $12.9 \mathrm{~g}$ in the groups using fortified milk and pure milk, respectively. In terms of growth, the authors demonstrated significantly higher linear growth in the group that received fortified milk $(1.04 \mathrm{~cm} /$ week $)$ in comparison with the control group $(0.86 \mathrm{~cm} /$ week $) .{ }^{14}$

The results found in the present study are similar to those found in the literature. However, the use of exclusive raw maternal milk can make it difficult to compare with other studies, since other studies used milk from milk banks or formula to complement the diet.

In spite of the short-term higher weight and height growth found in preterm infants who received fortified milk, its use has some limitations, since the commercial product makes it impossible to adjust the supplementation according to each child's need. Variation in the protein composition of maternal milk can have an influence on the growth of preterm newborns. In addition, standardized supplementation using fortifiers can cause lack or excess of proteins, associated with insufficient caloric intake. Therefore, some authors suggest other alternatives for human milk supplementation.

In a prospective randomized study involving 32 very low birth weight preterm infants fed maternal milk or donor milk, the authors suggested adjustable fortification, which consists in adding an extra amount of proteins to the standard fortification, controlling blood urea nitrogen level. The results show that higher protein intake seemed to improve linear growth in the group that received adjustable fortification; however, there was no significant difference. ${ }^{22}$

Individual fortification, which consists in the analysis of the composition of maternal milk and its supplementation using the necessary amount of nutrients with the purpose of making the diet meet the needs of the very low birth weight preterm infant, is suggested in another study. ${ }^{23}$ According to these authors, individual fortification makes it possible to establish a more accurate amount of calories and proteins, also reducing the risk of hyperosmolality. Using such principles in the nutrition of 10 very low birth weight preterm infants, the authors demonstrated the same weight gain we found in the present study $(21 \mathrm{~g} /$ day $)$.

With regard to clinical complications, there was no significant difference between the groups. Some authors highlighted the higher risk of necrotizing enterocolitis in newborns who are fed fortified milk due to the increase in osmolality. ${ }^{24}$ Because of its osmotic concentration, the persistent amylase activity in human milk, even after pasteurization, significantly increases osmolality of fortified maternal milk. Clinical experience shows that this increase in osmolality can be a risk factor for necrotizing enterocolitis in extreme preterm infants. ${ }^{25}$ In spite of that, it has been demonstrated that the risk of enterocolitis in newborns fed fortified human milk remains lower than the risk for those that receive formula. ${ }^{26}$ The effect of osmolality in pure and fortified human milk gradually stored for 10 minutes, 1 hour, 2 hours and up to 24 hours was analyzed. ${ }^{24}$ The authors found that there is gradual increase in osmolality of stored maternal milk, and when milk is offered to newborns immediately after the addition of fortifier, which was the method used in the present study, such effects can be reduced. ${ }^{27}$ In the present study, we did not diagnose necrotizing enterocolitis after randomization.

Based on the results of this study, we concluded that the supplementation with fortifier at a concentration of $5 \%$, after fluid intake reaches $100 \mathrm{~mL} / \mathrm{kg} /$ day, can result in a significant increase in growth. This is the first study conducted in Brazil using exclusively maternal raw milk in $100 \%$ of the diet offered, and it may prompt further studies in other centers. There is great difficulty in keeping mothers in a hospital setting, with maternal milk available for manual expression during the whole period of hospital stay, and this was only possible in the present study because mothers were offered accommodations during the whole period of study, in addition to nutritional and psychological follow-up provided by the multiprofessional and interdisciplinary team.

Despite the favorable results regarding the use of fortifiers, further studies are needed to improve and individualize the nutrition of very low birth weight preterm infants, taking into consideration the composition of maternal milk and each newborn's needs. It is possible that new studies might demonstrate results obtained with the use of fortifiers extracted from human milk.

\section{References}

1. Ziegler E, O'Donnel AM, Nelson SE, Formon SJ. Body composition of the reference fetus. Growth. 1976;40:329-41.

2. Gartner LM, Morton J, Lawrence RA, Naylor AJ, O'Hare D, Schanler RJ, et al. Breastfeeding and the use of human milk. Pediatrics. 2005;115:496-506. 
3. Morley R, Lucas A. Randomized diet in the neonatal period and growth performance until 7.5-8 y of age in preterm children. Am J Clin Nutr. 2000;71:822-8.

4. Effect of breastfeeding on infant and child mortality due to infectious diseases in less developed countries: a pooled analysis. WHO Collaborative Study Team on the Role of Breastfeeding on the Prevention of Infant Mortality. Lancet. 2000;355:451-55.

5. Vieira AA, Moreira ME, Rocha AD, Pimenta HP, Lucena SL. Análise do conteúdo energético do leite humano administrado a recém-nascidos de muito baixo peso ao nascimento. J Pediatr (Rio J). 2004;80:490-4.

6. Atkinson SA, Bryan $\mathrm{MH}$, Anderson GH. Human milk feeding in premature infants, protein, fat and carbohydrate balances in the first two weeks of life. J Pediatr. 1981;99:617-24.

7. Schanler RJ. Suitability of human milk for the low-birthweight infant. Clin Perinatol. 1995;22:207-22.

8. Schanler R. The use of human milk for premature infants. Pediatr Clin North Am. 2001;1:207-19.

9. Narayanan I, Prakash K, Bala S, Verma RK, Gujral VV. Partial supplementation with expressed breast-milk for prevention of infection in low-birth-weight infants. Lancet. 1980;2:561-3.

10. Schanler RJ, Garza C, Nichols BL. Fortified mothers' milk for very low birth weight infants: results of growth and nutrient balance studies. J Pediatr. 1985;107:437-45.

11. Steichen JJ, Krug-Wispé SK, Tsang RC. Breastfeeding the low birth weight preterm infant. Clin Perinatol. 1987;14:131-71.

12. Mussi-Pinhata MM, Rego MA. Immunological peculiarities of extremely preterm infants: a challenge for the prevention of nosocomial sepsis. J Pediatr (Rio J). 2005;81:S59-68.

13. Zuppa AA, Girlando P, Scapillati ME, Maggio L, Romagnoli C, Tortorolo G. Effects on growth, tolerability and biochemical parameters of two different human milk fortifiers in very low birth-weight newborns. Pediatr Med Chir. 2004;26:45-9.

14. Mukhopadhyay K, Narnag A, Mahajan R. Effect of human fortification in appropriate for gestation and small for gestation preterm babies: a randomized controlled trial. Indian Pediatr. 2007;44:286-90.

15. Kuzma-O'Reilly B, Duenas ML, Greecher C, Kimberlin L, Mujsce D, Miller D, et al. Evaluation, development, and implementation of potentially better practices in neonatal intensive care nutrition. Pediatrics. 2003; 111:e461-70.

16. Carey DE, Rowe JC, Goetz CA, Horak E, Clark RM, Goldberg B. Growth and phosphorus metabolism in premature infants fed human milk, fortified human milk, or special premature formula. Use of serum procollagen as a marker of growth. Am J Dis Child. 1987;141:511-5.
17. Pettifor JM, Rajah R, Venter A, Moodley GP, Opperman L, Cavaleros $\mathrm{M}$, et al. Bone mineralization and mineral homeostasis in very low-birth-weight infants fed either human milk or fortified human milk. J Pediatr Gastroenterol Nutr. 1989;8:217-24.

18. Loui A, Raab A, Wagner M, Weigel H, Grüters-Kieslich A, Bratter $P$, et al. Nutrition of very low birth weight infants fed human milk with or without supplemental trace elements: a randomized controlled trial. J Pediatr Gastroenterol Nutr. 2004;39:346-53.

19. Camelo Jr. JS, Martinez FE. Nutritional dilemmas in extremely low birth weight infants and their effects on childhood, adolescence and adulthood. J Pediatr (Rio J). 2005;81:33-42.

20. O'Connor DL, Jacobs J, Hall R, Adamkin D, Auestad N, Castillo M, et al. Growth and development of premature infants fed predominantly human milk, predominantly premature infant formula, or a combination of human milk and premature formula. J Pediatr Gastroenterol Nutr. 2003;37:437-46.

21. Kuschel CA, Harding JE. Multicomponent fortified human milk for promoting growth in preterm infants. Cochrane Database Syst Rev. 2004;CD000343.

22. Arslanoglu S, Moro GE, Ziegler EE. Adjustable fortification of human milk fed to preterm infants: does it make a difference? J Perinatol. 2006;26:614-21.

23. de Halleux V, Close A, Stalport S, Studzinski F, Habibi F, Rigo J. Intérêt de la supplémentation du lait maternel «à la carte ». Arch Pediatr. 2007;14:5-10.

24. Agarwal R, Singal A, Aggarwal R, Deorari AK, Paul VK. Effect of fortification with human milk fortifier (HMF) and other fortifying agents on the osmolality of preterm breast milk. Indian Pediatr. 2004;41:63-7.

25. Hallstrom M, Koivisto AM, Janas M, Tammela O. Frequency of and risk factors for necrotizing enterocolitis in infants born before 33 weeks of gestation. Acta Paediatr. 2003;92:111-3.

26. Heiman $H$, Schanler RJ. Enteral nutrition for premature infants: the role of human milk. Semin Fetal Neonatal Med. 2007;12: 26-34

27. Janjindamai $W$, Chotsampancharoen $T$. Effect of fortification on the osmolality of human milk. J Med Assoc Thai. 2006;89: 1400-3.

Correspondence:

Evelyn Conti Martins

Rua Via Láctea, 50

CEP 37904-046 - Passos, MG - Brazil

Tel.: + 55 (22) 9285.9729, +55 (35) 9106.8336

E-mail: evbil@uol.com.br 